Defective WNT signaling associates with bone marrow fibrosis-a cross-sectional cohort study in a family with WNT1 osteoporosis

Mäkitie, R. E.

2018-02

Mäkitie , R E , Niinimäki , R , Kakko , S , Honkanen , T , Kovanen , P E \& Mäkitie , O 2018 , ' Defective WNT signaling associates with bone marrow fibrosis-a cross-sectional cohort study in a family with WNT1 osteoporosis ', Osteoporosis International , vol. 29 , no. 2 , pp. 479-487 . https://doi.org/10.1007/s00198-017-4309-4

http://hdl.handle.net/10138/236692

https://doi.org/10.1007/s00198-017-4309-4

unspecified

acceptedVersion

Downloaded from Helda, University of Helsinki institutional repository.

This is an electronic reprint of the original article.

This reprint may differ from the original in pagination and typographic detail.

Please cite the original version. 


\title{
Defective WNT signaling associates with bone marrow fibrosis-a cross-sectional cohort study in a family with WNT1 osteoporosis
}

\author{
R. E. Mäkitie ${ }^{1}$ • R. Niinimäki ${ }^{2}$ S. Kakko ${ }^{3}$ - T. Honkanen ${ }^{4}$ - P. E. Kovanen ${ }^{5}$. \\ O. Mäkitie ${ }^{1,6,7}$
}

Received: 26 July 2017 / Accepted: 7 November 2017 / Published online: 16 November 2017

(C) International Osteoporosis Foundation and National Osteoporosis Foundation 2017

\begin{abstract}
Summary This study explores bone marrow function in patients with defective WNT1 signaling. Bone marrow samples showed increased reticulin and altered granulopoiesis while overall hematopoiesis was normal. Findings did not associate with severity of osteoporosis. These observations provide new insight into the role of WNT signaling in bone marrow homeostasis.

Introduction WNT signaling regulates bone homeostasis and survival and self-renewal of hematopoietic stem cells. Aberrant activation may lead to osteoporosis and bone marrow pathology. We aimed to explore bone marrow findings in a large family with early-onset osteoporosis due to a heterozygous WNT1 mutation.

Methods We analyzed peripheral blood samples, and bone marrow aspirates and biopsies from 10 subjects with WNT1 mutation p.C218G. One subject was previously diagnosed
\end{abstract}

with idiopathic myelofibrosis and others had no previously diagnosed hematologic disorders. The findings were correlated with the skeletal phenotype, as evaluated by number of peripheral and spinal fractures and bone mineral density. Results Peripheral blood samples showed no abnormalities in cell counts, morphology or distributions but mild increase in platelet count. Bone marrow aspirates (from $8 / 10$ subjects) showed mild decrease in bone marrow iron storages in 6 and variation in cell distributions in 5 subjects. Bone marrow biopsies (from 6/10 subjects) showed increased bone marrow reticulin (grade MF-2 in the myelofibrosis subject and grade MF-1 in 4 others), and an increase in overall, and a shift towards early-phase, granulopoiesis. The bone marrow findings did not associate with the severity of skeletal phenotype. Conclusions Defective WNT signaling associates with a mild increase in bone marrow reticulin and may predispose to

Electronic supplementary material The online version of this article (https://doi.org/10.1007/s00198-017-4309-4) contains supplementary material, which is available to authorized users.

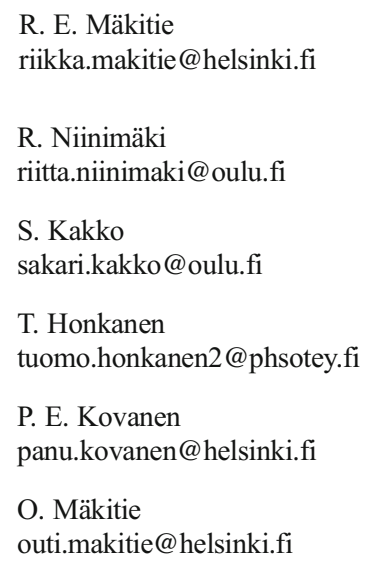

1 Folkhälsan Institute of Genetics, University of Helsinki, P.O. Box 63, FIN-00014 Helsinki, Finland

2 Department of Children and Adolescents, Oulu University Hospital and Oulu University, Oulu, Finland

3 Internal Medicine and Clinical Research Center, University of Oulu, Oulu, Finland

4 Department of Hematology, Päijät-Häme Central Hospital, Lahti, Finland

5 HUSLAB, Helsinki University Hospital and Department of Pathology, University of Helsinki, Helsinki, Finland

6 Children's Hospital, University of Helsinki and Helsinki University Hospital, Helsinki, Finland

7 Center for Molecular Medicine, Karolinska Institutet and Clinical Genetics, Karolinska University Hospital, Stockholm, Sweden 
myelofibrosis, while overall hematopoiesis and peripheral blood values are unaltered in individuals with a WNT1 mutation. In this family with WNT1 osteoporosis, bone marrow findings were not related to the severity of osteoporosis.

Keywords Hematopoiesis · Hematopoietic stem cells · Myelofibrosis · Osteoporosis · WNT signaling

\section{Introduction}

WNT signaling has an important role in bone health. Abnormal WNT signaling can lead to several skeletal disorders with reduced (e.g., osteoporosis-pseudoglioma syndrome, early-onset osteoporosis) or increased (van Buchem disease and sclerosteosis) bone mass [1-4]. We and others previously identified WNT1 as the key ligand for the WNT/ $\beta$-catenin pathway in bone and showed that loss-of-function WNT1 mutations lead to severe early-onset osteoporosis [5, 6]. In mice, Wnt1 was expressed in bone marrow, especially in the B cell lineage and hematopoietic progenitors; lineage tracing identified expression of the gene in a subset of osteocytes, suggesting that altered cross-talk between the hematopoietic and osteoblastic lineage cells may play a role in the pathogenesis of WNT1 osteoporosis [5]. However, the role of WNT signaling and effects of WNT1 mutations on bone marrow homeostasis remain unclear.

WNT signaling is an important mediator in hematopoiesis and maintenance of bone marrow homeostasis. WNTs are essential for survival of hematopoietic stem cells (HSCs) as they regulate the renewal and quiescence of primitive HSCs and stimulate their proliferation and progression towards lineage-specific-committed progenitor cells. [7-11] Prolonged WNT/ $\beta$-catenin stimulus, on the other hand, may prevent HSCs from their ability to repopulate and differentiate properly, which may ultimately lead to bone marrow failure [12]. WNT signaling may also predispose to bone marrow pathology; it is dysregulated in myeloproliferative neoplasms and disorders $[13,14]$ and communicates with other bone marrow pathology -related factors, such as transforming growth factor beta (TGF- $\beta$ ) [15]. The exact role of WNT signaling, the key WNT ligands, and the coactivators or inhibitors participating in hematopoietic homeostasis, however, remain yet to be established.

Our initial studies on WNT1 concerned a large Finnish family with early-onset osteoporosis due to a heterozygous missense mutation p.C218G in WNT1 [5]. The mutated WNT1 leads to reduced WNT/ $\beta$-catenin-signaling and low osteoblastic function, low bone mass and fractures in children and adolescents, and to severe osteoporosis in adults [5, 16]. One of our WNT1 mutation-positive subjects was diagnosed with idiopathic primary myelofibrosis (PMF) and some other family members reported a history of anemia. Considering the interactions between bone tissue and bone marrow and the importance of WNT signaling therein [17], and expression of WNT1 in bone marrow [5], we hypothesized that defective WNT1 signaling would cause changes in bone marrow and hematopoiesis in WNT1 mutation-positive individuals.

\section{Materials and methods}

\section{Subjects}

Our index family includes 20 family members with a heterozygous WNT1 missense mutation c.652T>G (p.C218G) [5, 16]. All have been carefully phenotyped for skeletal features, as reported previously $[14,16,18]$, by dual-energy X-ray absorptiometry (DXA), spinal radiography and/or spinal magnetic resonance imaging (MRI). We offered all mutation-positive adults an opportunity to participate in further studies concerning the characteristic of WNT1 osteoporosis, including hematologic and bone marrow features. Nine subjects consented and comprised the study cohort (hereafter: COHORT). For the family member with diagnosed PMF (hereafter: INDEX), we collected and reanalyzed previously obtained clinical, hematologic and PMF treatment -related data, including bone marrow samples. We also inquired about dietary habits and possible dietary restrictions. The study was approved by the Institutional Research Ethics Board. All study subjects gave their written informed consent before participation.

\section{Genetic evaluations}

We performed genetic validations on DNA from peripheral blood as previously described [16]. The presence of the heterozygous mutation c.652T>G (p.C218G) in WNT1 (National Center for Biotechnology Information [NCBI] Reference Sequence [RefSeq], NM_005430.3) was confirmed in all participants.

\section{Biochemical and hematologic evaluations}

We obtained peripheral blood samples for the COHORT and assessed them for complete blood count with differential, parameters of calcium, phosphate, and iron homeostasis, hemoglobin isoelectric focusing, and peripheral blood cell morphology. For the INDEX, we used the peripheral blood sample results obtained at the time of PMF diagnosis. We compared results with the NordLab reference values and report them according to the general guidelines formed by the International Council for Standardization in Hematology (ICSH) [19].

\section{Bone marrow samples}

We obtained bone marrow aspirate and biopsy samples according to normal protocols in local anesthesia from posterior 
iliac crest with a standard aspirate and trephine needles. Due to technical or patient-related reasons, reliable bone marrow aspirate and biopsy samples were not obtained for all and were available for $7 / 9$ and $5 / 9$ subjects in the COHORT, respectively. For the INDEX, we re-examined bone marrow samples obtained at the time of PMF diagnosis in 2010 simultaneously with the other samples. All aspirate samples were first reviewed by a laboratory hematologist at NordLab at the Oulu University Hospital. Aspirate and biopsy samples were then reviewed by an experienced hematopathologist (P.E.K.) at the Department of Pathology (HUSLAB), Helsinki University Hospital, who was blinded to the subjects' clinical status and diagnosis.

Bone marrow aspirate samples were assessed for overall quality, cellularity and cell type distribution. As advised by International Council for Standardization in Hematology (ICSH), at least 500 cells were counted from each sample to obtain precise percentages [19]. All results are reported according to the ICSH guidelines for the standardization of bone marrow specimens and reports [19].

Bone marrow core biopsy samples were assessed for overall microscopic microarchitecture, cellularity, and cell morphology using hematoxylin and eosin staining for cell morphology, chloroacetate esterase for granulocytic lineage, CD3and CD20-staining for lymphocyte immunohistochemistry, periodic acid-Schiff staining for polysaccharides and reticulin staining for fibrosis. The amount of reticulin (marrow fibrosis, MF) was graded MF0-3 according to the European Consensus on grading of bone marrow fibrosis [20]; MF-0, scattered linear fibers with no intersections; MF-1, loose fibers with many intersections; MF-2, diffuse and dense increase with extensive intersections; MF-3, as in MF-2 but also with coarse bundles of collagen. All results are presented according to the ICSH guidelines for bone marrow samples [21]. Giemsa staining was used for G-band analysis of chromosomes.

\section{Correlations with skeletal features}

We collected fracture histories, BMD data and radiological data from spinal imaging, and compared the findings with bone marrow findings. We classified each of the skeletal and bone marrow parameters into three categories of increasing severity to evaluate the possible associations between bone marrow findings and skeletal changes, osteoporosis treatment, gender and subject's age.

\section{Results}

\section{Cohort characteristic}

In addition to the INDEX, an adult female with PMF, the study COHORT included six females and three males from the same family (age range 33-76 years, median age 45 years) with varying severity of skeletal changes (Table 1, Supplemental Fig. 1). Out of the whole cohort of 10 subjects, 5 had prior or on-going osteoporosis medication at the time of the study. None received iron supplementation. All followed a normal diet and none had any specific dietary restrictions at the time of the study.

\section{Findings in the INDEX with WNT1 mutation and myelofibrosis}

The 39-year-old female (AIII-1, Fig. 1) was diagnosed with osteoporosis in 2006; a disease-causing heterozygous WNT1 mutation was confirmed. She had a history of four peripheral fractures, three vertebral compression fractures on spinal radiographs and only osteopenic BMD (Table 1). Osteoporosis medication was not initiated. Four years later, routine control tests indicated elevated liver enzymes: alanine transaminase (ALT) $169 \mathrm{U} / \mathrm{L}$ (normal <35 U/L), aspartate transaminase (AST) $55 \mathrm{U} / \mathrm{L}$ (normal range 15-35 U/L), alkaline phosphatase (ALP) $225 \mathrm{U} / \mathrm{L}$ (normal range 35-105 U/L), and glutamyltransferase (GT) 208 (normal < 40 U/L). An abdominal ultrasound revealed a large thrombus obstructing the portal vein and extending into the lienal and superior mesenteric veins. Abdominal CT and MRI showed a pathologic liver structure and slight splenomegaly. Blood samples revealed mild thrombocytosis $\left(634 \times 10^{9} / \mathrm{L}\right)$, prolonged prothrombin time, and slightly increased lactase dehydrogenase while hemoglobin, leukocytes and erythrocyte parameters were normal (Supplemental Table 1). A bone marrow aspirate showed fibrotic and firm bone marrow fragments and an increased number of clustered and morphologically abnormal megakaryocytes (Table 2). A trephine biopsy from iliac crest confirmed megakaryocyte hyperplasia and increased fibrosis; sample showed extensive increase in reticulin (MF-2) and clusters of large megakaryocytes (Table 3 and Fig. 1a). Bone marrow cell culture with mononuclear stem cells showed no spontaneous erythrocyte or megakaryocyte proliferation. Genetic studies for the Janus Kinase 2 (JAK2) mutation and chromosomal studies for Philadelphia-chromosome were negative and a diagnosis of idiopathic myelofibrosis was set. Interferon treatment was not commenced, as she remained stable during follow-up.

\section{Findings in the COHORT with WNT1 mutation}

In peripheral blood samples obtained from nine other family members without known hematologic pathology, no significant changes were detected; complete blood count showed normal hemoglobin in all but one subject who had mild anemia, and normal erythrocyte and leukocyte counts (Supplemental Table 1). Platelet count was elevated in one. Differential leukocyte count showed overall normal 
Table 1 Clinical findings in 10 adults with a heterozygous p.C218G WNT1 mutation

\begin{tabular}{|c|c|c|c|c|c|c|c|c|c|c|}
\hline Subject (sex, age in years) & $\mathrm{F}, 39^{*}$ & $\mathrm{~F}, 33$ & $\mathrm{~F}, 43$ & $\mathrm{~F}, 51$ & M, 51 & $\mathrm{~F}, 52$ & M, 62 & $\mathrm{~F}, 70$ & $\mathrm{~F}, 73$ & M, 75 \\
\hline Pedigree code & AIII-1* & AIII-2 & AIII-5 & AIII-6 & AIII-4 & AIII-3 & AII-1 & AII-2 & AII-3 & AII-4 \\
\hline Peripheral fractures & 5 & 2 & 0 & 0 & 2 & 0 & 3 & 9 & 6 & 1 \\
\hline VCFs & 3 & 0 & 0 & 0 & 3 & 6 & 7 & 8 & 9 & 5 \\
\hline BMD LS & -1.6 & -1.5 & -1.4 & N/A & -2.8 & -2.0 & -2.2 & -1.5 & -0.8 & 0.5 \\
\hline BMD Fem neck & -1.7 & -2.2 & -0.9 & N/A & -1.3 & -0.8 & -1.3 & -1.6 & -1.6 & 0.1 \\
\hline Prior osteoporosis medication & $\mathrm{N}$ & $\mathrm{N}$ & $\mathrm{N}$ & $\mathrm{N}$ & N/A & $\mathrm{Y}^{*}$ & $\mathrm{Y}$ & $\mathrm{Y}$ & $\mathrm{Y}^{*}$ & $\mathrm{Y}$ \\
\hline
\end{tabular}

$\mathrm{VCF}=$ vertebral compression fractures; $\geq 20 \%$ decrease in vertebral height. $\mathrm{BMD}=$ bone mineral density; measured with dual-energy X-ray absorptiometry, values converted to age- and gender-adjusted Z-scores. $\mathrm{LS}=$ lumbar spine. $\mathrm{Fem}=$ femoral. $\mathrm{Y}=\mathrm{yes} ; \mathrm{N}=$ no; N/A=not available; $*=$ bisphosphonate treatment on-going at the time of the study

distribution in all subjects but one had mild neutropenia and one, lymphopenia. Microscopy of peripheral blood cells showed no abnormalities. EPO was normal in all. Ferritin was low in one subject and elevated in three. Lactase dehydrogenase was elevated in two subjects. Calcium and phosphate concentrations were low in two subjects, and parathyroid hormone and ALP levels were slightly increased in one and two subjects, respectively (Supplemental Table 1).

Bone marrow aspirates were obtained from seven of the nine subjects in the COHORT (Table 2). In general, the samples had normal cellularity and cellular morphology in all subjects and there were no signs of increased precursor cells. Megakaryocytes and lymphocytes were normal in amount and morphology while one subject (AIII-2) had some megakaryocytes with over-lobulated and fragmented nuclei, similar to the INDEX. Four were low in storage iron and two had a reduced number of sideroblasts. No infiltrates of abnormal or malignant cells were seen in any of the samples.

Bone marrow core biopsies were obtained from five subjects in the COHORT (Table 3, Figs. 1 and 2). The size of the biopsies ranged from 15 to $20 \mathrm{~mm}$ and the area covered by hematopoietic cells ranged from 50 to $70 \%$. Four biopsies had increased and shifted towards early-phase granulopoiesis (Fig. 2a). Two subjects had small infiltrates of reactive lymphocytes as assessed by immunostainings. Three subjects had minor eosinophilia (Fig. 2b). All subjects had normal chromosome number, correct sex chromosomes and no signs of clonal chromosome changes upon Giemsa G-band staining.

The core biopsies showed increase in reticulin fiber in four of the five subjects (Table 3, Figs. 1b, c). In one of the five biopsies, technical issues prevented assessment of reticulin and hence reticulin was increased in all samples that could
Fig. 1 Iliac bone marrow biopsies from three adult subjects with heterozygous p.C218G WNT1 mutation. a The 39 -yearold female INDEX (AIII-1) with diagnosed myelofibrosis. Two COHORT subjects, b a 33-yearold female (AIII-2) and c a 62year-old male (AII-1).

Microscopic findings show in all an increase in bone marrow reticulin (arrows). $\times 400$ resolution

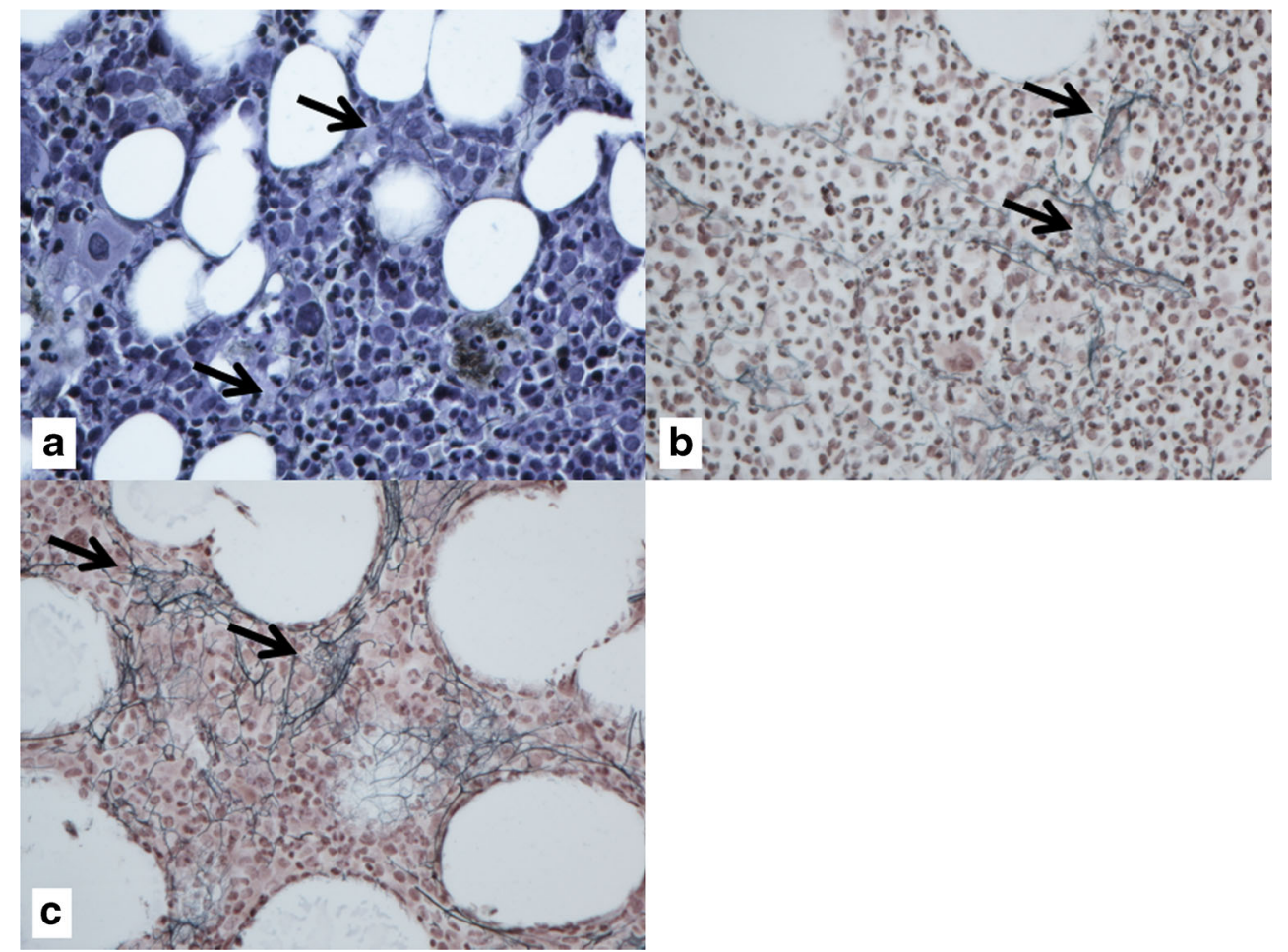


Table 2 Bone marrow aspirate findings in 8 adults with a heterozygous p.C218G WNT1 mutation
Table 3 Bone marrow biopsy findings in 6 adults with a heterozygous p.C218G WNT1 mutation

\begin{tabular}{|c|c|c|c|c|c|c|c|c|}
\hline Subject (sex, age in years) & $\mathrm{F}, 39^{*}$ & F, 33 & $\mathrm{~F}, 43$ & $\mathrm{~F}, 51$ & M, 51 & $\mathrm{~F}, 52$ & $M, 62$ & M, 75 \\
\hline Pedigree code & AIII- $1 *$ & AIII-2 & AIII-5 & AIII-6 & AIII-4 & AIII-3 & AII-1 & AII-4 \\
\hline Cellularity & $\mathrm{N}$ & $\mathrm{N}$ & $\mathrm{N}$ & $\mathrm{N}$ & $\mathrm{N}$ & $\mathrm{N}$ & $\mathrm{N}$ & $\mathrm{N}$ \\
\hline Blasts $(\%)$ & $\mathrm{N}$ & 0.8 & 0.2 & 1.6 & 0.4 & 1.1 & N/A & N/A \\
\hline Megakaryocytes & I & $\mathrm{N}$ & $\mathrm{N}$ & $\mathrm{N}$ & $\mathrm{N}$ & $\mathrm{N}$ & $\mathrm{N}$ & $\mathrm{N}$ \\
\hline Promyelocytes (\%) & N/A & 2.6 & 3.4 & 1.4 & 1.5 & 4.3 & $\mathrm{~N} / \mathrm{A}$ & N/A \\
\hline Myelocytes (\%) & N/A & 25.4 & 22.1 & 18.0 & 18.4 & 23.1 & N/A & N/A \\
\hline $\begin{array}{l}\text { Metamyelocytes } \\
\text { and bands (\%) }\end{array}$ & N/A & 18.3 & 15.5 & 12.3 & 10.7 & 10.1 & $\mathrm{~N}$ & $\mathrm{~N}$ \\
\hline Neutrophils (\%) & $\mathrm{N}$ & 20.9 & 17.0 & 21.4 & 16.2 & 18.2 & $\mathrm{~N}$ & $\mathrm{~N}$ \\
\hline Eosinophils, early (\%) & $\mathrm{N}$ & 0.2 & 0.2 & 1.0 & 1.0 & 4.7 & $\mathrm{~N}$ & $\mathrm{~N}$ \\
\hline Basophils (\%) & $\mathrm{N}$ & 0 & 0 & 0.6 & 0 & 0 & $\mathrm{~N}$ & $\mathrm{~N}$ \\
\hline Monocytes (\%) & $\mathrm{N}$ & 0.4 & 0.9 & 0.8 & 0.2 & 0.2 & N/A & N/A \\
\hline Pronormoblasts (\%) & N/A & 0.2 & 0.2 & 0.6 & 0.2 & 0.2 & N/A & N/A \\
\hline Basophilics (\%) & $\mathrm{N}$ & 0.6 & 1.7 & 2.0 & 0.4 & 0.9 & $\mathrm{~N}$ & $\mathrm{~N}$ \\
\hline Polychromatics (\%) & N/A & 13.8 & 10.5 & 18.4 & 14.9 & 8.1 & N/A & N/A \\
\hline Orthochromatics (\%) & N/A & 4.7 & 6.2 & 6.5 & 17.3 & 11.6 & $\mathrm{~N} / \mathrm{A}$ & N/A \\
\hline Lymphocytes (\%) & I & 11.2 & 20.2 & 13.5 & 14.2 & 12.4 & $\mathrm{~N}$ & $\mathrm{~N}$ \\
\hline Plasmacells (\%) & $\mathrm{N}$ & 0.4 & 1.1 & 0.2 & 2.7 & 1.3 & $\mathrm{~N}$ & $\mathrm{~N}$ \\
\hline Histiocytes & $\mathrm{N}$ & $\mathrm{N}$ & $\mathrm{N}$ & $\mathrm{N}$ & $\mathrm{N}$ & $\mathrm{N}$ & $\mathrm{N}$ & $\mathrm{N}$ \\
\hline Mast cells & $\mathrm{N}$ & $\mathrm{N}$ & $\mathrm{N}$ & $\mathrm{N}$ & $\mathrm{N}$ & $\mathrm{N}$ & $\mathrm{N}$ & $\mathrm{N}$ \\
\hline Iron storage & $+/-$ & - & - & - & ++ & + & ++ & + \\
\hline Sideroblasts & + & N/A & - & + & + & + & N/A & $-/+$ \\
\hline
\end{tabular}

The INDEX subject with diagnosed primary myelofibrosis indicated with an asterisk (AIII-1). Supranormal values are underlined and subnormal values are in italics. Normal ranges according Wintrobe's Clinical Hematology 11th ed [22]

$N$ normal, $I$ increased

\begin{tabular}{lllllll}
\hline Pedigree code & AIII-1* & AIII-2 & AIII-5 & AIII-6 & AII-1 & AII-4 \\
\hline Cellularity (\%) & 65 & 70 & 55 & 55 & 50 & 50 \\
Reticulin (0-3) & 2 & 1 & 1 & N/A & 1 & 1 \\
Megakaryocytes (N/I/D) & $\mathrm{I}$ & $\mathrm{N}$ & $\mathrm{N}$ & $\mathrm{N}$ & $\mathrm{N}$ & $\mathrm{N}$ \\
Megakaryocyte morphology & Hyperlobulation; large, & $\mathrm{N}$ & $\mathrm{N}$ & $\mathrm{N}$ & $\mathrm{N}$ & $\mathrm{N}$ \\
& dispersed, clusters & & & & & \\
Granulopoiesis (\%) & 60 & 55 & 50 & 50 & 60 & 60 \\
Granulopoiesis (\%. early:late) & $55: 45$ & $50: 50$ & $60: 40$ & $50: 50$ & $50: 50$ & $30: 70$ \\
Granulopoiesis (N/I/D) & $\mathrm{I}++$ & $\mathrm{I}+$ & $\mathrm{I}+$ & $\mathrm{I}+$ & $\mathrm{I}+$ & $\mathrm{N}$ \\
Erythropoiesis (\%) & 30 & 25 & 30 & 35 & 30 & 20 \\
Erythropoiesis (normal:early) & $\mathrm{Early+}$ & $\mathrm{N}$ & $\mathrm{N}$ & $\mathrm{N}$ & $\mathrm{N}$ & $\mathrm{N}$ \\
Lymphocytes & 10 & 20 & 10 & 15 & 10 & 10 \\
Lymphocytes & 3 & 1 & 2 & 0 & 1 & 2 \\
Eosinophils & $<5$ & $<5$ & 10 & $<5$ & 5 & 10 \\
Plasma cells (N///D) & $\mathrm{N}$ & $\mathrm{N}$ & $\mathrm{N}$ & $\mathrm{N}$ & $\mathrm{N}$ & $\mathrm{N}$ \\
Blasts (N/I/D) & $\mathrm{N}$ & $\mathrm{N}$ & $\mathrm{N}$ & $\mathrm{N}$ & $\mathrm{N}$ & $\mathrm{N}$ \\
Histiocytes (N/I/D) & $\mathrm{N}$ & $\mathrm{N}$ & $\mathrm{N}$ & $\mathrm{N}$ & $\mathrm{N}$ & $\mathrm{N}$ \\
\hline
\end{tabular}

The INDEX subject with diagnosed primary myelofibrosis indicated with an asterisk (AIII-1). Supranormal values are underlined and subnormal values are in italics. Normal ranges according Wintrobe's Clinical Hematology 11th ed [22]

$N$ normal, $I$ increased, $D$ decreased 


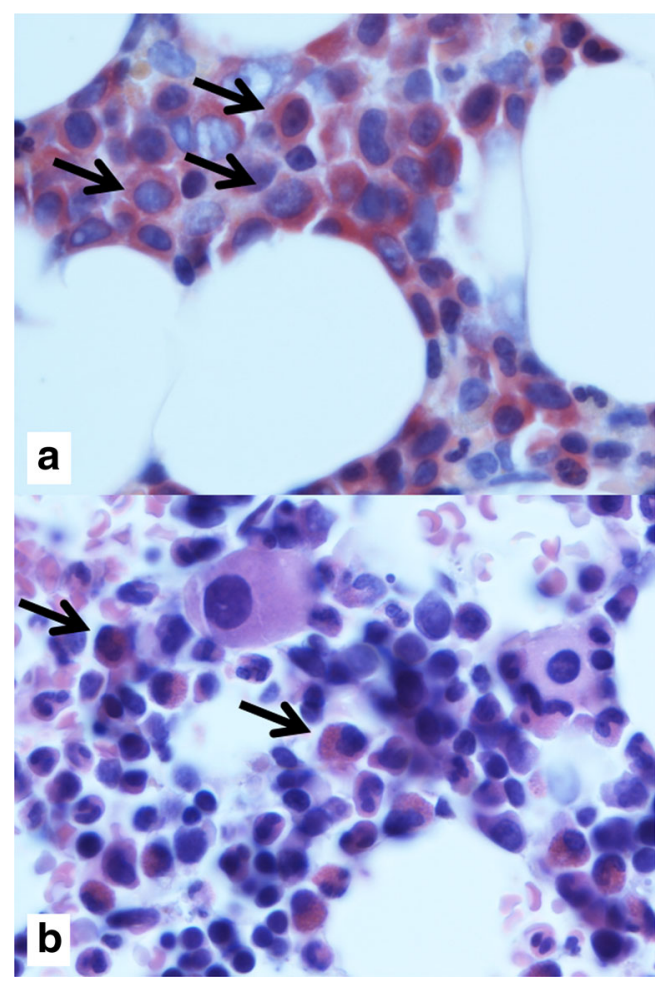

Fig. 2 Iliac bone marrow biopsy from two adults with a heterozygous p.C218G WNT1 mutation. a A 43-year-old female subject (AIII-5), microscopic findings show increase in early phase granulopoiesis (examples of chloroacetate esterase (leder)-positive myelocytes indicated by arrows). b A 75-year-old male subject (AII-4), microscopic findings show mild eosinophilia (arrows) (H\&E-staining). $\times 100$ resolution

be properly analyzed. These changes were mild and classified as grade MF-1 (on scale 0-3) in the four subjects, as compared with the grade MF-2 in the INDEX with PMF. The amount of marrow reticulin did not associate with age, sex or menopausal status as these four COHORT subjects ranged in age from 33 to 75 years and represented both sexes. Like the INDEX, these four subjects also had increased and shifted towards early-phase granulopoiesis. In two subjects, bone marrow iron storages were depleted with a low number of sideroblasts. The overall marrow cellularity was only increased in one COHORT subject (AIII-2), and megakaryocyte morphology and erythropoiesis were normal.

\section{Association between skeletal and bone marrow findings}

The INDEX (AIII-1) with the most severe bone marrow fibrosis had a relatively mild skeletal phenotype with osteopenia and three spinal fractures (Table 1, Fig. 3a). The four other subjects with mild increase in bone marrow fibrosis had variable skeletal pathologies; two of them had no spinal compression fractures and only osteopenic BMD, while two of them had significant skeletal changes with several compression fractures (Table 1, Fig. 3b-d). Overall, there was no association between the bone marrow findings and the severity of osteoporosis as evaluated from the number of fractures and bone mineral density (Supplemental Fig. 2). Further, bone marrow changes were not related to age. Two subjects with bone marrow fibrosis, as well as the INDEX, were naïve to any osteoporosis medication.

\section{Discussion}

This is the first study to report bone marrow findings in adult subjects with impaired WNT signaling; all 10 evaluated individuals harbored a heterozygous WNT1 mutation. Our INDEX subject was diagnosed with primary myelofibrosis while the nine other subjects had no previously diagnosed hematologic diseases. In line with our hypothesis, four COHORT subjectsall whose bone marrow biopsy could be properly evaluatedpresented with slightly increased bone marrow reticulin. Peripheral blood profiles in the nine COHORT subjects were similar to those of the INDEX (e.g., normal hemoglobin levels, platelet counts close to the upper normal limit, and leukocyte counts close to the lower normal limit) and a shift towards early-phase granulopoiesis. Bone marrow findings did not associate with severity of skeletal phenotype.

Diffuse bone marrow reticulin is not seen in healthy individuals. Therefore, it is reasonable to hypothesize that aberrant WNT1 signaling due to the WNT1 mutation underlies increased reticulin formation in our study COHORT and primary myelofibrosis in our INDEX. While WNTs' role in bone marrow fibrosis remains underdetermined, recent studies have shown that $\beta$-catenin induces bone marrow fibrosis indirectly through fibrocytic and immunoregulatory responses [23], that canonical $\mathrm{WNT} / \beta$-catenin pathway is dysregulated in PMF [7], and that $\beta$-catenin expression is increased in PMF [24]. Furthermore, it is known that there lies direct crosstalk and positive feedback between TGF- $\beta$, an activator of fibroblast collagen synthesis and inducer of marrow fibrosis [25], and WNT signaling [9]. Also of note, WNT signaling is known to contribute to several other fibrotic diseases involving such tissues as the lungs, kidneys, and heart [26-28].

Our main aim was to study whether the WNT1 mutation p.C218G causes increased bone marrow fibrosis and would be linked to the PMF diagnosed in one of our subjects with WNT1 osteoporosis. Myelofibrosis is a malignant myeloproliferative disorder with neoplastic clonal proliferation of a single multipotent hematopoietic stem cell. Common clinical features include severe anemia, mild leukopenia, thrombocytosis, and splenomegaly, and bone marrow biopsies portray a pathologic population of megakaryocytes, an increase in reticular fibers and, at later stages, collagen fibrosis (osteosclerosis) [29, 30]. Majority of MF patients have a mutation in $J A K 2, M P L$, or $C A L R$ [30-34]. Altogether, $60 \%$ of primary myelofibrosis cases are caused by a dominant, gain-of-function $\mathrm{p}$.V617F mutation in 
Fig. 3 Spinal radiographs and magnetic resonance images of four subjects with a heterozygous p.C218G WNT1 mutation and bone marrow fibrosis. a The 39year-old female INDEX (AIII-1) with diagnosed myelofibrosis. Three COHORT subjects, b a 33year-old female (AIII-2), c a 43year-old female (AIII-5), and $\mathbf{d}$ a 62-year-old male (AII-1)

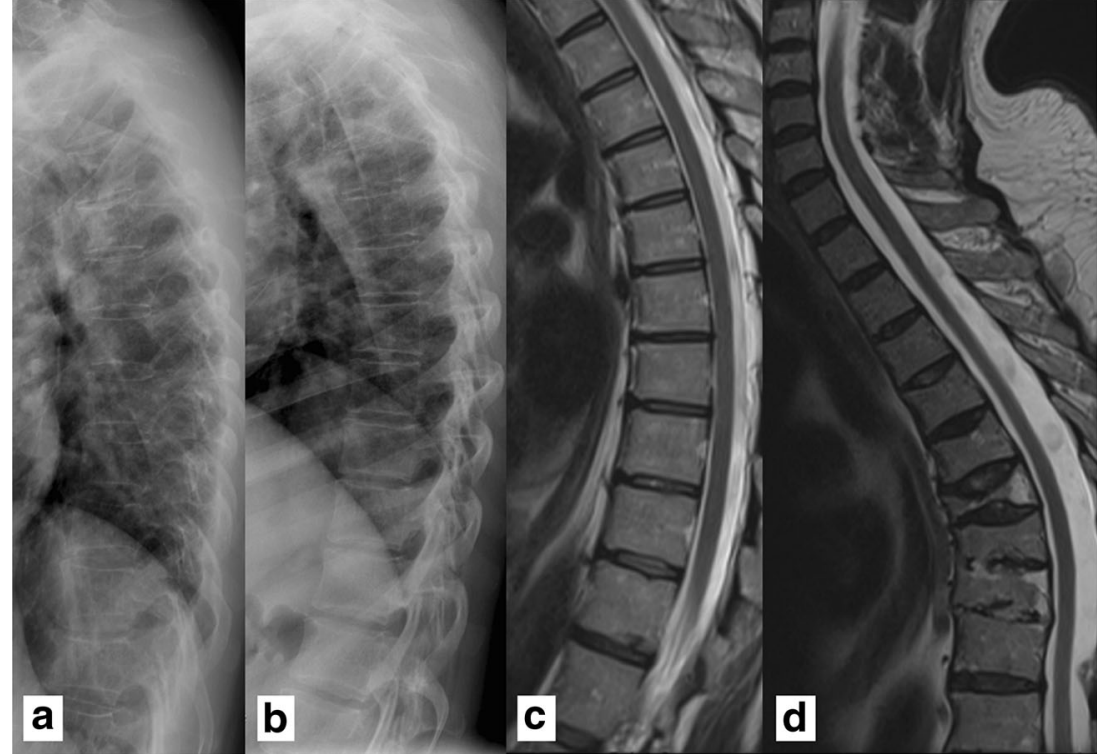

$J A K 2$, which is known to cause also a large portion of polycythemia vera and essential thrombocytosis cases [30-34]. While the $J A K 2$ mutation was excluded in our INDEX, no studies were performed for possible $M P L$ or $C A L R$ variations. However, bone marrow stem cell cultures indicated no spontaneous myeloproliferation typically observed in MPL- and CALR-positive cases, suggesting that the WNT1 mutation could account for our INDEX subject's findings.

Mature osteoblasts partake in accommodating HSCs in the osteoblastic bone marrow niche near endosteum and WNT signaling directly participates in the niche-mediated regulation of HSC maintenance and differentiation [35, 36]. Certain WNT ligands are specifically expressed in bone marrow and regulate hematopoiesis. Luis et al. have hypothesized that WNT3a would solely carry this function as it nonredundantly regulates HSC function and lack of its stimulus results in complete absence of WNT signaling. However, WNT5A and WNT11 signal through noncanonical WNT pathways and also assist in hematopoietic processes [37-39]. Our findings indicate that WNT1 may play a role in maintenance of the hematopoietic niche and regulation of stem cells. Of note, the severity of osteoporosis or prior or on-going osteoporosis medication did not seem to impact the hematologic bone marrow findings. Also, there are no reports of myelofibrosis, other bone marrow changes, or severe hematologic abnormalities in individuals with homozygous WNT1 mutations. These together indicate that the changes in bone marrow are independent and not secondary to the changes in adjacent trabecular and cortical bone tissue and, hence, a direct consequence of aberrant WNT1 signaling.

Besides reticulin formation, other mild changes were also seen that underscore the role of aberrant WNT signaling in bone marrow pathology. Firstly, three subjects in our COHORT presented with low iron storage and four subjects with a reduced sideroblast number. In the INDEX with PMF, iron storages were low but sideroblasts were visible. Many malignant processes of the bone marrow can hamper iron storages; leukemia and other proliferative conditions displace erythropoietic cells and cause diminished iron stores [40] and, while bone marrow smears may show low sideroblasts and deplete iron storages, peripheral blood concentrations of hemoglobin and iron may remain normal [41]. Secondly, two subjects had mild eosinophilia. Although causes of eosinophilia are numerous, both primary and secondary, several studies have characterized eosinophils as a part of the malignant clone in myeloid neoplasms and myeloproliferative diseases arising from mutated multipotent myeloid stem cells [42-44], which supports the possibility that ineffective WNT signaling could give rise to the mild eosinophilia through inadequate stem cell differentiation. However, there was no eosinophilia in the PMF subject and therefore its connection to aberrant WNT signaling remains to be studied.

Our study does have limitations primarily concerning the cohort size. A greater number of samples from all age groups would provide more sound and reliable results and perhaps reveal minor systematic changes that now escaped our attention. However, bone marrow biopsy, as an invasive procedure, can be difficult to obtain due to either subject- or ethics-related restrictions. Our study is the first of its kind and therefore, despite the limited cohort size, the results are important and require validation in other cohorts. In addition, the WNTI point mutation p.C218G causes a decrease in but not a complete disruption of WNT signaling, which may explain why our findings are quite subtle. There are also other WNT ligands that activate WNT signaling in bone and bone marrow and they could partially alleviate the effects of decreased WNT1 activity. Future studies could explore the expression levels of b-catenin in peripheral blood or bone marrow biopsies from WNT1 mutation-positive subjects, which we were unable to evaluate in the scope of this study. Despite these 
restrictions, WNT1 mutations have only been described in a handful of families worldwide and we therefore regard our data rare and unique.

In conclusion, aberrant WNT1 signaling due to the heterozygous p.C218G mutation in WNT1 causes a mild increase in bone marrow reticulin that could be related to primary myelofibrosis but other bone marrow changes are mild and variable. The bone marrow findings did not associate with the severity of osteoporosis phenotype. Our study provides exceptional and valuable data on bone marrow changes in impaired WNT1 signaling. As new osteoporosis therapies targeting the WNT signaling pathway are in development, a thorough understanding of the clinically significant effects of the signaling pathway in extra-skeletal tissues is important also for the growing population receiving medical treatment for osteoporosis.

Acknowledgements All research protocols were approved by the Research Ethics Board of Helsinki University Hospital, Helsinki, Finland. All study subjects gave their written informed consent before participation.

Funding This study was financially supported by the Sigrid Jusélius Foundation, the Folkhälsan Research Foundation, the Academy of Finland, the Foundation for Pediatric Research, the Helsinki University Research Funds, the Swedish Research Council, the Novo Nordisk Foundation, the Swedish Childhood Cancer Foundation, Helsinki University and Helsinki University Hospital through the Doctoral Programme in Clinical Research, the Biomedicum Helsinki Foundation, the Finnish Medical Foundation, the Jalmari and Rauha Ahokas Foundation, and through the regional agreement on medical training and clinical research (ALF) between Stockholm County Council and Karolinska Institutet.

\section{Compliance with ethical standards}

Conflicts of interest None.

\section{References}

1. Gong Y, Slee RB, Fukai N, Rawadi G, Roman-Roman S, Reginato AM, Wang H, Cundy T, Glorieux FH, Lev D, Zacharin M, Oexle K, Marcelino J, Suwairi W, Heeger S, Sabatakos G, Apte S, Adkins WN, Allgrove J, Arslan-Kirchner M, Batch JA, Beighton P, Black GC, Boles RG, Boon LM, Borrone C, Brunner HG, Carle GF, Dallapiccola B, de Paepe A, Floege B, Halfhide ML, Hall B, Hennekam RC, Hirose T, Jans A, Jüppner H, Kim CA, KepplerNoreuil K, Kohlschuetter A, LaCombe D, Lambert M, Lemyre E, Letteboer T, Peltonen L, Ramesar RS, Romanengo M, Somer H, Steichen-Gersdorf E, Steinmann B, Sullivan B, Superti-Furga A, Swoboda W, van den Boogaard MJ, van Hul W, Vikkula M, Votruba M, Zabel B, Garcia T, Baron R, Olsen BR, Warman ML, Osteoporosis-Pseudoglioma Syndrome Collaborative Group (2001) Osteoporosis-pseudoglioma syndrome collaborative group. LDL receptor-related protein 5 (LRP5) affects bone accrual and eye development. Cell 107(4):513-523. https://doi.org/10.1016/S00928674(01)00571-2

2. Saarinen A, Saukkonen T, Kivelä T, Lahtinen U, Laine C, Somer M, Toiviainen-Salo S, Cole WG, Lehesjoki AE, Mäkitie O (2010) Low density lipoprotein receptor-related protein 5 (LRP5) mutations and osteoporosis, impaired glucose metabolism and hypercholesterolaemia. Clin Endocrinol 72(4):481-488. https://doi. org/10.1111/j.1365-2265.2009.03680.x

3. Loots GG, Kneissel M, Keller H, Baptist M, Chang J, Collette NM, Ovcharenko D, Plajzer-Frick I, Rubin EM (2005) Genomic deletion of a long-range bone enhancer misregulates sclerostin in Van Buchem disease. Genome Res 15(7):928-935. https://doi.org/10. 1101/gr.3437105

4. Balemans W, Ebeling M, Patel N, van Hul E, Olson P, Dioszegi M, Lacza C, Wuyts W, van den Ende J, Willems P, Paes-Alves AF, Hill S, Bueno M, Ramos FJ, Tacconi P, Dikkers FG, Stratakis C, Lindpaintner K, Vickery B, Foernzler D, van Hul W (2001) Increased bone density in sclerosteosis is due to the deficiency of a novel secreted protein (SOST). Hum Mol Genet 10(5):537-543. https://doi.org/10.1093/hmg/10.5.537

5. Laine CM, Joeng KS, Campeau PM, Kiviranta R, Tarkkonen K, Grover M, Lu JT, Pekkinen M, Wessman M, Heino TJ, NieminenPihala V, Aronen M, Laine T, Kröger H, Cole WG, Lehesjoki AE, Nevarez L, Krakow D, Curry CJR, Cohn DH, Gibbs RA, Lee BH, Mäkitie O (2013) WNT1 mutations in early-onset osteoporosis and osteogenesis imperfecta. N Engl J Med 368(19):1809-1816. https:// doi.org/10.1056/NEJMoa1215458

6. Keupp K, Beleggia F, Kayserili H, Barnes AM, Steiner M, Semler O, Fischer B, Yigit G, Janda CY, Becker J, Breer S, Altunoglu U, Grünhagen J, Krawitz P, Hecht J, Schinke T, Makareeva E, Lausch E, Cankaya T, Caparrós-Martín JA, Lapunzina P, Temtamy S, Aglan M, Zabel B, Eysel P, Koerber F, Leikin S, Garcia KC, Netzer C, Schönau E, Ruiz-Perez VL, Mundlos S, Amling M, Kornak U, Marini J, Wollnik B (2013) Mutations in WNT1 cause different forms of bone fragility. Am J Hum Genet 92(4):565-574. https://doi.org/10.1016/j.ajhg.2013.02.010

7. Mohammed MK, Shao C, Wang J, Wei Q, Wang X, Collier Z, Tang S, Liu H, Zhang F, Huang J, Guo D, Lu M, Liu F, Liu J, Ma C, Shi LL, Athiviraham A, He TC, Lee MJ (2016) Wnt/ $\beta$-catenin signaling plays an ever-expanding role in stem cell self-renewal, tumorigenesis and cancer chemoresistance. Genes Dis 3(1):11-40. https:// doi.org/10.1016/j.gendis.2015.12.004

8. Reya T, Duncan AW, Ailles L, Domen J, Scherer DC, Willert K, Hintz L, Nusse R, Weissman IL (2003) A role for Wnt signaling in self-renewal of hematopoietic stem cells. Nature 423(6938):409 414. https://doi.org/10.1038/nature01593

9. Austin TW, Solar GP, Ziegler FC, Liem L, Matthews WA (1997) Role for the Wnt gene family in hematopoiesis: expansion of multilineage progenitor cells. Blood 89(10):3624-3635

10. Baba Y, Yokota T, Spits H, Garrett KP, Hayashi S, Kincade PW (2006) Constitutively active beta-catenin promotes expansion of multipotent hematopoietic progenitors in culture. J Immunol 177(4):2294-2303. https://doi.org/10.4049/jimmunol.177.4.2294

11. Murdoch B, Chadwick K, Martin M, Shojaei F, Shah KV, Gallacher L, Moon RT, Bhatia M (2003) Wnt-5A augments repopulating capacity and primitive hematopoietic development of human blood stem cells in vivo. Proc Natl Acad Sci U S A 100(6):3422-3427. https://doi.org/10.1073/pnas.0130233100

12. Kirstetter P, Anderson K, Porse BT, Jacobsen SE, Nerlov C (2006) Activation of the canonical Wnt pathway leads to loss of hematopoietic stem cell repopulation and multilineage differentiation block. Nat Immunol 7(10):1048-1056. https://doi.org/10.1038/ni1381

13. Lucijanic M, Livun A, Tomasovic-Loncaric C, Stoos-Veic T, Pejsa V, Jaksic O, Prka Z, Kusec R (2016) Canonical Wnt/ $\beta$-catenin signaling pathway is dysregulated in patients with primary and secondary myelofibrosis. Clin Lymphoma Myeloma Leuk. 16(9): 523-526. https://doi.org/10.1016/j.clml.2016.06.004

14. Jauregui MP, Sanchez SR, Ewton AA, Rice L, Perkins SL, Dunphy $\mathrm{CH}$, Chang CC (2008) The role of beta-catenin in chronic myeloproliferative disorders. Hum Pathol 39(10):1454-1458. https://doi. org/10.1016/j.humpath.2008.02.007 
15. Piersma B, Bank RA, Boersema M (2015) Signaling in fibrosis: TGF- $\beta$, WNT, and YAP/TAZ converge. Front Med (Lausanne) 2: 59. https://doi.org/10.3389/fmed.2015.00059

16. Mäkitie RE, Haanpää M, Valta H, Pekkinen M, Laine CM, Lehesjoki AE, Schalin-Jäntti C, Mäkitie O (2016) Skeletal characteristics of WNT1 osteoporosis in children and young adults. J Bone Miner Res 31(9):1734-1742. https://doi.org/10.1002/jbmr.2841

17. Taichman RS (2005) Blood and bone: two tissues whose fates are intertwined to create the hematopoietic stem-cell niche. Blood 105(7):2631-2639. https://doi.org/10.1182/blood-2004-06-2480

18. Mäkitie RE, Niinimäki T, Nieminen MT, Schalin-Jäntti C, Niinimäki J, Mäkitie O (2017) Impaired WNT signaling and the spine-heterozygous WNT1 mutation causes severe age-related spinal pathology. Bone 101:3-9. https://doi.org/10.1016/j.bone.2017. 04.001

19. Lee SH, Erber WN, Porwit A, Tomonaga M, Peterson LC (2008) International Council for Standardization in Hematology. ICSH guidelines for the standardization of bone marrow specimens and reports. Int J Lab Hematol 30(5):349-364. https://doi.org/10.1111/j. 1751-553X.2008.01100.x

20. Thiele J, Kvasnicka HM, Facchetti F, Franco V, van der Walt J, Orazi A (2005) European consensus on grading of bone marrow fibrosis and assessment of cellularity. Haematologica 90(8):1128-1132

21. Torlakovic EE, Brynes RK, Hyjek et al (2015) International Council for Standardization in Haematology. ICSH guidelines for the standardization of bone marrow immunohistochemistry. Int $\mathrm{J}$ Lab Hematol 37(4):431-449. https://doi.org/10.1111/ijlh.12365

22. Greer JP, Arber DA, Glader B et al Wintrobe's clinical hematology, vol 17, 11th edn. Lippincott Williams \& Wilkins, Philadelphia, p 2004

23. Yu J, Cao J, Li H, Liu P, Xu S, Zhou R, Yao Z, Guo X (2016) Bone marrow fibrosis with fibrocytic and immunoregulatory responses induced by $\beta$-catenin activation in osteoprogenitors. Bone 84:3846. https://doi.org/10.1016/j.bone.2015.12.003

24. Geduk A, Atesoglu EB, Tarkun P, Mehtap O, Hacihanefioglu A, Demirsoy ET, Baydemir C (2015) The role of $\beta$-catenin in Bcr/Abl negative myeloproliferative neoplasms: an immunohistochemical study. Clin Lymphoma Myeloma Leuk 15(12):785-789. https:// doi.org/10.1016/j.clm1.2015.08.084

25. Agarwal A, Morrone K, Bartenstein M, Zhao ZJ, Verma A, Goel S (2016) Bone marrow fibrosis in primary myelofibrosis: pathogenic mechanisms and the role of TGF- $\beta$. Stem Cell Investig 3:5. https:// doi.org/10.3978/j.issn.2306-9759.2016.02.03

26. Chilosi M, Poletti V, Zamò A, Lestani M, Montagna L, Piccoli P, Pedron S, Bertaso M, Scarpa A, Murer B, Cancellieri A, Maestro R, Semenzato G, Doglioni C (2003) Aberrant Wnt/beta-catenin pathway activation in idiopathic pulmonary fibrosis. Am J Pathol 162(5): 1495-1502. https://doi.org/10.1016/S0002-9440(10)64282-4

27. Surendran K, McCaul SP, Simon TCA (2002) Role for Wnt-4 in renal fibrosis. Am J Physiol Renal Physiol 282(3):F431-F441. https://doi.org/10.1152/ajprenal.0009.2001

28. Tao H, Yang JJ, Shi KH, Li J (2016) Wnt signaling pathway in cardiac fibrosis: new insights and directions. Metabolism 65(2): 30-40. https://doi.org/10.1016/j.metabol.2015.10.013

29. Vardiman JW, Thiele J, Arber DA, Brunning RD, Borowitz MJ, Porwit A, Harris NL, le Beau MM, Hellstrom-Lindberg E, Tefferi A, Bloomfield CD (2009) The 2008 revision of the World Health Organization (WHO) classification of myeloid neoplasms and acute leukemia: rationale and important changes. Blood 114(5):937-951. https://doi.org/10.1182/blood-2009-03-209262

30. Tefferi A (2000) Myelofibrosis with myeloid metaplasia. N Engl J Med 342(17):1255-1265. Review. https://doi.org/10.1056/ NEJM200004273421706

31. Baxter EJ, Scott LM, Campbell PJ et al (2005) Cancer genome project. Acquired mutation of the tyrosine kinase JAK2 in human myeloproliferative disorders. Lancet 365(9464):1054-1061 Erratum in: Lancet 2005;366:122

32. Levine RL, Wadleigh M, Cools J, Ebert BL, Wernig G, Huntly BJP, Boggon TJ, Wlodarska I, Clark JJ, Moore S, Adelsperger J, Koo S, Lee JC, Gabriel S, Mercher T, D'Andrea A, Fröhling S, Döhner K, Marynen P, Vandenberghe P, Mesa RA, Tefferi A, Griffin JD, Eck MJ, Sellers WR, Meyerson M, Golub TR, Lee SJ, Gilliland DG (2005) Activating mutation in the tyrosine kinase JAK2 in polycythemia vera, essential thrombocythemia, and myeloid metaplasia with myelofibrosis. Cancer Cell 7(4):387-397. https://doi.org/10. 1016/j.ccr.2005.03.023

33. Pikman Y, Lee BH, Mercher T et al (2006) MPLW515L is a novel somatic activating mutation in myelofibrosis with myeloid metaplasia. PLoS Med e270:3

34. Klampfl T, Gisslinger H, As H et al (2013) Somatic mutations of calreticulin in myeloproliferative neoplasms. N Engl J Med 369(25):2379-2390. https://doi.org/10.1056/NEJMoa1311347

35. Zhang J, Niu C, Ye L, Huang H, He X, Tong WG, Ross J, Haug J, Johnson T, Feng JQ, Harris S, Wiedemann LM, Mishina Y, Li L (2003) Identification of the hematopoietic stem cell niche and control of the niche size. Nature 425(6960):836-841. https://doi.org/ 10.1038/nature02041

36. Calvi LM, Adams GB, Weibrecht KW, Weber JM, Olson DP, Knight MC, Martin RP, Schipani E, Divieti P, Bringhurst FR, Milner LA, Kronenberg HM, Scadden DT (2003) Osteoblastic cells regulate the hematopoietic stem cell niche. Nature 425(6960):841846. https://doi.org/10.1038/nature02040

37. Luis TC, Naber BA, Fibbe WE, van Dongen JJ, Staal FJ (2010) Wnt3a nonredundantly controls hematopoietic stem cell function and its deficiency results in complete absence of canonical Wnt signaling. Blood 116(3):496-497. https://doi.org/10.1182/blood2010-04-282624

38. Luis TC, Weerkamp F, Naber BA, Baert MR et al (2009) Wnt3a deficiency irreversibly impairs hematopoietic stem cell self-renewal and leads to defects in progenitor cell differentiation. Blood 113(3): 546-554. https://doi.org/10.1182/blood-2008-06-163774

39. Schreck C, Bock F, Grziwok S, Oostendorp RA, Istvánffy R (2014) Regulation of hematopoiesis by activators and inhibitors of Wnt signaling from the niche. Ann N Y Acad Sci 1310(1):32-43. https://doi.org/10.1111/nyas.12384

40. Cervantes F, López-Guillermo A, Piera C, Pereira A, Aguilar JL, Ordi J, Rozman C (1993) Initial iron deposits in idiopathic myelofibrosis. Analysis of 20 subjects. Sangre (Barc) 38(4):279-282

41. Cervantes F, Rozman C, Piera C, Fernandez MR (1986) Decreased bone marrow iron in chronic granulocytic leukaemia: a consistent finding not reflecting iron deficiency. Blutalkohol 53:305-308

42. Matsushima T, Handa H, Yokohama A, Nagasaki J, Koiso H, Kin Y, Tanaka Y, Sakura T, Tsukamoto N, Karasawa M, Itoh K, Hirabayashi H, Sawamura M, Shinonome S, Shimano S, Miyawaki S, Nojima Y, Murakami H (2003) Prevalence and clinical characteristics of myelodysplastic syndrome with bone marrow eosinophilia or basophilia. Blood 101(9):3386-3390. https://doi. org/10.1182/blood-2002-03-0947

43. Forrest DL, Horsman DE, Jensen CL, Berry BR, Dalal BI, Barnett MJ, Nantel SH (1998) Myelodysplastic syndrome with hypereosinophilia and a nonrandom chromosomal abnormality $\operatorname{dic}(1 ; 7)$ : confirmation of eosinophil clonal involvement by fluorescence in situ hybridization. Cancer Genet Cytogenet 107(1):65-68. https://doi.org/10.1016/S0165-4608(98)00055-7

44. Schwaab J, Jawhar M, Naumann N, Schmitt-Graeff A, Fabarius A, Horny HP, Cross NCP, Hofmann WK, Reiter A, Metzgeroth G (2016) Diagnostic challenges in the work up of hypereosinophilia: pitfalls in bone marrow core biopsy interpretation. Ann Hematol 95(4):557-562. https://doi.org/10.1007/s00277-016-2598-x 